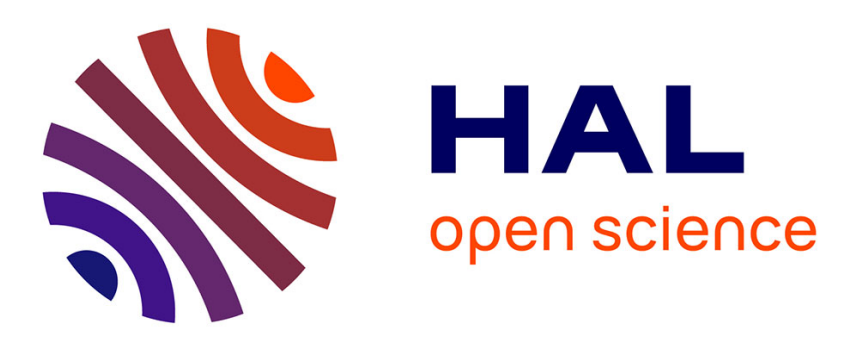

\title{
Artificial ducts caused by HF heating of the ionosphere by HAARP
}

A. Vartanyan, G. M. Milikh, E. Mishin, Michel Parrot, I. Galkin, B. Reinisch, J. Huba, G. Joyce, K. Papadopoulos

\section{> To cite this version:}

A. Vartanyan, G. M. Milikh, E. Mishin, Michel Parrot, I. Galkin, et al.. Artificial ducts caused by HF heating of the ionosphere by HAARP. Journal of Geophysical Research Space Physics, 2012, 117 (A10), 11 p. 10.1029/2012JA017563 . insu-01295706

\section{HAL Id: insu-01295706 https://hal-insu.archives-ouvertes.fr/insu-01295706}

Submitted on 20 May 2016

HAL is a multi-disciplinary open access archive for the deposit and dissemination of scientific research documents, whether they are published or not. The documents may come from teaching and research institutions in France or abroad, or from public or private research centers.
L'archive ouverte pluridisciplinaire HAL, est destinée au dépôt et à la diffusion de documents scientifiques de niveau recherche, publiés ou non, émanant des établissements d'enseignement et de recherche français ou étrangers, des laboratoires publics ou privés. 


\title{
Artificial ducts caused by HF heating of the ionosphere by HAARP
}

\author{
A. Vartanyan, ${ }^{1}$ G. M. Milikh, ${ }^{1}$ E. Mishin, ${ }^{2}$ M. Parrot,${ }^{3}$ I. Galkin, ${ }^{4}$ B. Reinisch, ${ }^{4}$ J. Huba,${ }^{5}$ \\ G. Joyce, ${ }^{1,6}$ and K. Papadopoulos ${ }^{1}$ \\ Received 27 January 2012; revised 13 July 2012; accepted 10 August 2012; published 5 October 2012.
}

[1] We report on satellite observations of plasma density enhancements (ducts) in the topside ionosphere during four HAARP/BRIOCHE campaigns during 2009-2010. Artificial ducts, caused by high-power HF radio wave injections from the HAARP transmitter toward the magnetic zenith, are detected by the DEMETER and DMSP satellites on a regular basis when there is a perceptible ionospheric $F_{2}$ peak density. Overall, the plasma density enhancements detected between 0930 and $1230 \mathrm{LT}$ varied from $3-13 \%$, while those during $\sim 1730-2215$ LT were typically $15-40 \%$. We also used a modified SAMI2 model to study the artificial ducts' mechanism driven by HF electron heating in the bottomside $F_{2}$ region. The heating builds up the plasma pressure, thus pushing plasma along the magnetic field. The simulation results performed for the input parameters similar to the conditions of the heating experiments are in fair agreement with the pertinent observations. The ducts seem to be produced most efficiently for heating frequencies quite close to the critical frequency $\mathrm{f}_{\mathrm{o}} \mathrm{F}_{2}$.

Citation: Vartanyan, A., G. M. Milikh, E. Mishin, M. Parrot, I. Galkin, B. Reinisch, J. Huba, G. Joyce, and K. Papadopoulos (2012), Artificial ducts caused by HF heating of the ionosphere by HAARP, J. Geophys. Res., 117, A10307, doi:10.1029/2012JA017563.

\section{Introduction}

[2] Field-aligned density enhancements (ducts) with $\mathrm{km}$ or longer length-scale can guide whistler waves along the geomagnetic field $\mathrm{B}_{0}$ [Streltsov et al., 2007]. Whistler waves generated by lighting discharges or very low frequency (VLF) transmitters, guided by such ducts into the magnetosphere, are known to play an important role on the radiation belts' dynamics [e.g., Koons, 1989; Carpenter et al., 2002]. Recently, Milikh et al. [2008] and Frolov et al. [2008] reported Detection of Electro-Magnetic Emissions Transmitted from Earthquake Regions (DEMETER) and Defense Meteorological Satellite Program (DMSP) satellite observations of artificial ducts in the topside ionosphere during ionospheric modification experiments at the High-frequency Active

\footnotetext{
${ }^{1}$ Department of Physics and Department of Astronomy, University of Maryland, College Park, Maryland, USA.

${ }^{2}$ Space Vehicles Directorate, Air Force Research Laboratory, Albuquerque, New Mexico, USA.

${ }^{3}$ Laboratoire de Physique et Chimie de l'Environnement et de l'Espace, CNRS, Orleans, France.

${ }^{4}$ Center for Atmospheric Research, University of Massachusetts, Lowell, Massachusetts, USA.

${ }^{5}$ Plasma Physics Division, Naval Research Laboratory, Washington, D. C., USA.

${ }^{6}$ Deceased 4 December 2011.

Corresponding author: A. Vartanyan, Department of Physics, University of Maryland, College Park, MD 20742, USA.

(aramvar@umd.edu)

C2012. American Geophysical Union. All Rights Reserved. 0148-0227/12/2012JA017563
}

Auroral Research Program (HAARP) and the Sura heating facilities. The physics of duct formation involves highfrequency (HF) heating of the bottomside $\mathrm{F}$ region of the ionosphere, followed by plasma outflow along the magnetic field lines [e.g., Perrine et al., 2006; Milikh et al., 2010a]. Such outflows were detected by the EISCAT Incoherent Scatter Radar (ISR) during heating experiments using the EISCAT heater at Tromsø [Rietveld et al., 2003], and by the DMSP satellites [Milikh et al., 2010b]. In our earlier papers [Milikh et al., 2008; Milikh and Vartanyan, 2010] we presented the first observations of ducts produced by HAARP and detected by DEMETER during 2007-2008 experiments. Those observations along with similar observations made during SURA/DEMETER experiments [Frolov et al., 2008] showed feasibility of artificial duct formation by ionospheric HF heating and thus stimulated extensive research efforts.

[3] It is the objective of this paper to present the results of a recent systematic study of the physics controlling the formation of artificial ionospheric ducts. In this study the ducts were driven by $\mathrm{F}$ region heating using the HAARP Ionospheric Research Instrument (IRI) and diagnosed by overflying satellites, the HAARP Digisonde, and a coherent radar located at Kodiak Island. The observations were compared with the predictions of a numerical model based on the modified SAMI2 code.

[4] The paper is organized as follows: Section 2 discusses the conduct of the experiments, including the diagnostic instrumentation, and also presents the key experimental results. Section 3 describes the modified SAMI2 model and compares its predictions to the observations. The final section, 
Table 1. A Summary of Relevant Information for Each Heating Experiment ${ }^{\mathrm{a}}$

\begin{tabular}{|c|c|c|c|c|c|c|c|c|}
\hline Satellite/ Date & $\begin{array}{l}\text { Heating Time } \\
\text { (UT) }\end{array}$ & $\mathrm{f}_{\mathrm{H}}(\mathrm{MHz}) / \mathrm{h}(\mathrm{km})$ & $\mathrm{f}_{0} \mathrm{~F}_{2}(\mathrm{MHz}) / \mathrm{h}_{\mathrm{m}} \mathrm{F}_{2}(\mathrm{~km})$ & $\Delta \mathrm{R}(\mathrm{km}) / \mathrm{L}_{\mathrm{EW}}(\mathrm{km})$ & $\begin{array}{l}\Delta \mathrm{V}_{\mathrm{i}} \\
(\mathrm{m} / \mathrm{s})\end{array}$ & $\begin{array}{c}\Delta \mathrm{n}_{\mathrm{i}} / \mathrm{n}_{\mathrm{i}}^{0} \\
(\%)\end{array}$ & Kodiak & $\begin{array}{l}\mathrm{AL} \\
(\mathrm{nT})\end{array}$ \\
\hline DEMETER 10/16/09 & $20: 15-20: 45$ & $5.1(\mathrm{CW})$ & $5.0-5.1 / 210$ & $69 / 32$ & N.A. & 11 & Strong reflection & 10 \\
\hline DEMETER 10/19/09 & $20: 00-20: 30$ & 5.4 & $5.4-5.8 / 200$ & $27 / 28$ & N.A. & 5 & Moderate reflection & 20 \\
\hline DEMETER 10/21/09 & $06: 15-06.30$ & $2.8(\mathrm{CW})$ & $2.0 / 210$ & $27 / 58$ & N.A. & 21 & N.A. & 3 \\
\hline DMSP F15 02/04/10 & $2: 10-2: 29$ & 4.0 & $4.0 / 240$ & $45 / 46$ & 300 & 30 & N.A. & 5 \\
\hline DMSP F16 02/09/10 & $17: 40-17: 59$ & $2.8 / 200$ & $3.4 / 240$ & $65 / 55$ & 70 & 8 & N.A. & 3 \\
\hline DMSP F16 02/10/10 & $03: 30-03: 50$ & $2.85 / 220$ & $3.6 / 250$ & $10 / 60$ & 250 & 40 & N.A. & 5 \\
\hline DEMETER 02/10/10 & $20: 15-20: 34$ & 4.25 & $5.2-5.5 / 210$ & $40 / 39$ & N.A. & 3 & N.A. & 100 \\
\hline DMSP F15 02/11/10 & 02:00-02:19 & $4.25(\mathrm{CW})$ & $4.9 / 230$ & $25 / 41$ & 80 & 8 & N.A. & 15 \\
\hline DEMETER 06/17/10 & $20: 15-20: 35$ & $2.85 / 150$ & $4.0-4.5 / 180$ & $141 / 40$ & N.A. & 5 & Weak reflection & 250 \\
\hline DMSP F16 06/19/10 & $3: 20-3: 40$ & $2.85 / 150$ & $4.2-4.5 / 220$ & $54 / 40$ & 20 & 3 & N.A. & 40 \\
\hline DMSP F18 06/24/10 & $18: 45-19: 00$ & 5.2 & $4.1-5.2 / 180$ & $76 / 27$ & 50 & 4 & Strong reflection & 50 \\
\hline DMSP F16 06/26/10 & $17.25-17: 45$ & 4.3 & $4.0-4.4 / 220$ & $56 / 40$ & 30 & 5 & Strong reflection & 250 \\
\hline DEMETER 10/28/10 & $19: 55-20: 15$ & $5.5(\mathrm{CW})$ & $5.2-5.9 / 220$ & $28 / 30$ & N.A. & 8 & N.A. & 100 \\
\hline DMSP F15 10/31/10 & $01: 45-01: 50$ & $5.6(\mathrm{CW})$ & $5.3 / 230$ & $66 / 31$ & 70 & 5 & Strong reflection & 2 \\
\hline DMSP F16 11/01/10 & $17: 25-17: 45$ & 4.1 & $3.7-4.1 / 230$ & $87 / 43$ & 55 & 6 & Strong reflection & 10 \\
\hline DEMETER 11/04/10 & $20: 10-20: 30$ & $5.4(\mathrm{CW})$ & $5.1 / 220$ & $151 / 31$ & N.A. & 5 & N.A. & 3 \\
\hline DMSP F15 11/07/10 & $01: 32-01: 44$ & $5.05(\mathrm{CW})$ & $4.7-5.7 / 240$ & $30 / 38$ & 100 & 15 & N.A. & 4 \\
\hline DEMETER 11/07/10 & $20: 05-20: 25$ & $6.5(\mathrm{CW})$ & $6.5-7.0 / 220$ & $56 / 26$ & N.A. & 13 & N.A. & 200 \\
\hline DEMETER 11/09/10 & $06: 05-06: 25$ & $2.8(\mathrm{CW})$ & $1.8 / 310$ & $46 / 85$ & N.A. & 22 & N.A. & 120 \\
\hline DMSP F16 11/10/10 & $03: 20-03: 40$ & $2.85(\mathrm{CW})$ & $3.0 / 230$ & $96 / 62$ & 270 & 75 & N.A. & 10 \\
\hline
\end{tabular}

${ }^{a}$ The columns (from left to right) are: name of satellite and date of experiment; time of heating; HF heating frequency ( $\mathrm{f}_{\mathrm{H}}$ ) and reflection height $\mathrm{h}$ (the absence of $\mathrm{h}$ in the table means that $\left.\mathrm{h}=\mathrm{h}_{\mathrm{m}} \mathrm{F}_{2}\right) ; \mathrm{F}_{2}$-peak frequency $\left(\mathrm{f}_{0} \mathrm{~F}_{2}\right)$ and $\mathrm{F}_{2}$-peak height $\left(\mathrm{h}_{\mathrm{m}} \mathrm{F}_{2}\right)$; distance of the closest approach to the HAARP MZ $(\Delta \mathrm{R})$ and E-W full-width-half-maximum size of the heated spot $\left(\mathrm{L}_{\mathrm{EW}}\right)$; upward change in ion velocity measured by satellite $\left(\Delta \mathrm{V}_{\mathrm{i}}\right)$; relative ion density perturbation in the duct measured by satellite $\left(\Delta n_{i} / n_{i}^{0}\right)$; Kodiak observations of wave reflections; Geomagnetic Auroral Electrojet (AL index).

Section 4, discusses the implications of the work and future experimental efforts.

\section{Experimental Observations}

[5] Four experimental campaigns were conducted at HAARP, during the period from October 2009 to November 2010. In all of these campaigns the HAARP HF heater operated at the maximum 3.6 megawatt (MW) power available, O-mode polarization, and the beam directed along the HAARP magnetic zenith (MZ). The HF heating frequency was chosen in such way that it either matched the ionospheric critical frequency $\left(\mathrm{f}_{\mathrm{o}} \mathrm{F}_{2}\right)$ or coincided with the second electron gyro harmonic $(2.8 \mathrm{MHz})$. The former frequency was used for daytime ionospheric heating, while the latter frequency was used during nighttime to effectively pump ionospheric turbulence. The modified ionosphere was sensed by instruments aboard the DEMETER microsatellite and by the DMSP satellites available at the time of the experiment. The satellite observations were complemented by ground based diagnostics provided by the HAARP Digisonde and the Kodiak radar.

\subsection{Ionospheric Diagnostics Used in the Experiments}

[6] The French microsatellite DEMETER, which was in operation till December 2010, follows a circular $(670 \mathrm{~km}$ altitude) sun-synchronous polar orbit. DEMETER flies over HAARP two times a day, during nighttime at 6-7 UT (2223 LT), and during daytime at 20-21 UT (12-13 LT). The distance between the satellite and the HAARP MZ varies from about $10 \mathrm{~km}-500 \mathrm{~km}$ due to orbit precession. Since we are interested in close overflies of less than $100 \mathrm{~km}$ from the HAARP MZ, the number of useful orbits is limited to approximately 1-2 per week. Throughout the study we have used DEMETER's Plasma Analyzer Instrument (Instrument Analyseur de Plasma, IAP) and Langmuir Probe Instrument
(Instrument Sonde de Langmuir, ISL) as topside diagnostic tools. At the time of our experiments, DEMETER's instruments were operated in "burst" mode, allowing a sampling rate of $0.43 \mathrm{~Hz}$ for the IAP and $1 \mathrm{~Hz}$ for the ISL.

[7] The DMSP satellites fly in circular (840 km altitude) sun-synchronous polar orbits. Although less sensitive than DEMETER, the constellation of DMSP satellites provides HAARP overfly coverage of a few times a day. Restriction of overflies to within $100 \mathrm{~km}$ of the HAARP MZ limits the number of useful orbits to about 4-5 per week. We used the SSIES suite of sensors that measures the ion densities and drift motions of ionospheric ions [Rich and Hairston, 1994]. The horizontal $\left(\mathrm{V}_{\mathrm{H}}\right)$ and vertical $\left(\mathrm{V}_{\mathrm{V}}\right)$ components of the plasma drift velocity have a measurement range of $\pm 3 \mathrm{~km} / \mathrm{s}$ with one-bit resolution of $\Delta \mathrm{V}=12 \mathrm{~m} / \mathrm{s}$, provided $\mathrm{n}_{\mathrm{i}} \geq 5000 \mathrm{~cm}^{-3}$. It takes $4 \mathrm{~s}$ to sample the ion composition, while the plasma drift and density are sampled at rates of 6 and $24 \mathrm{~Hz}$, respectively.

[8] The satellite observations were complemented by ground based diagnostics that include the HAARP Digisonde and the Kodiak HF coherent radar. The Digisonde provided a set of ionograms that helped us choose a proper heating frequency. In addition, during the last three campaigns the Digisonde operated in the sky map mode. This mode allows one to obtain directional ionograms by probing several frequencies below and above the heating frequency in a short amount of time as well as to measure reflections from the plasma irregularities. The directional ionograms give a rough estimate of the plasma drift velocities in the bottomside $\mathrm{F}$ region.

\subsection{Observational Details}

[9] During the last four campaigns we have in total used about 60 DEMETER and DMSP overflies, which occurred during different daytime conditions and seasons, as well as under quiet and perturbed ionospheric conditions. Table 1 

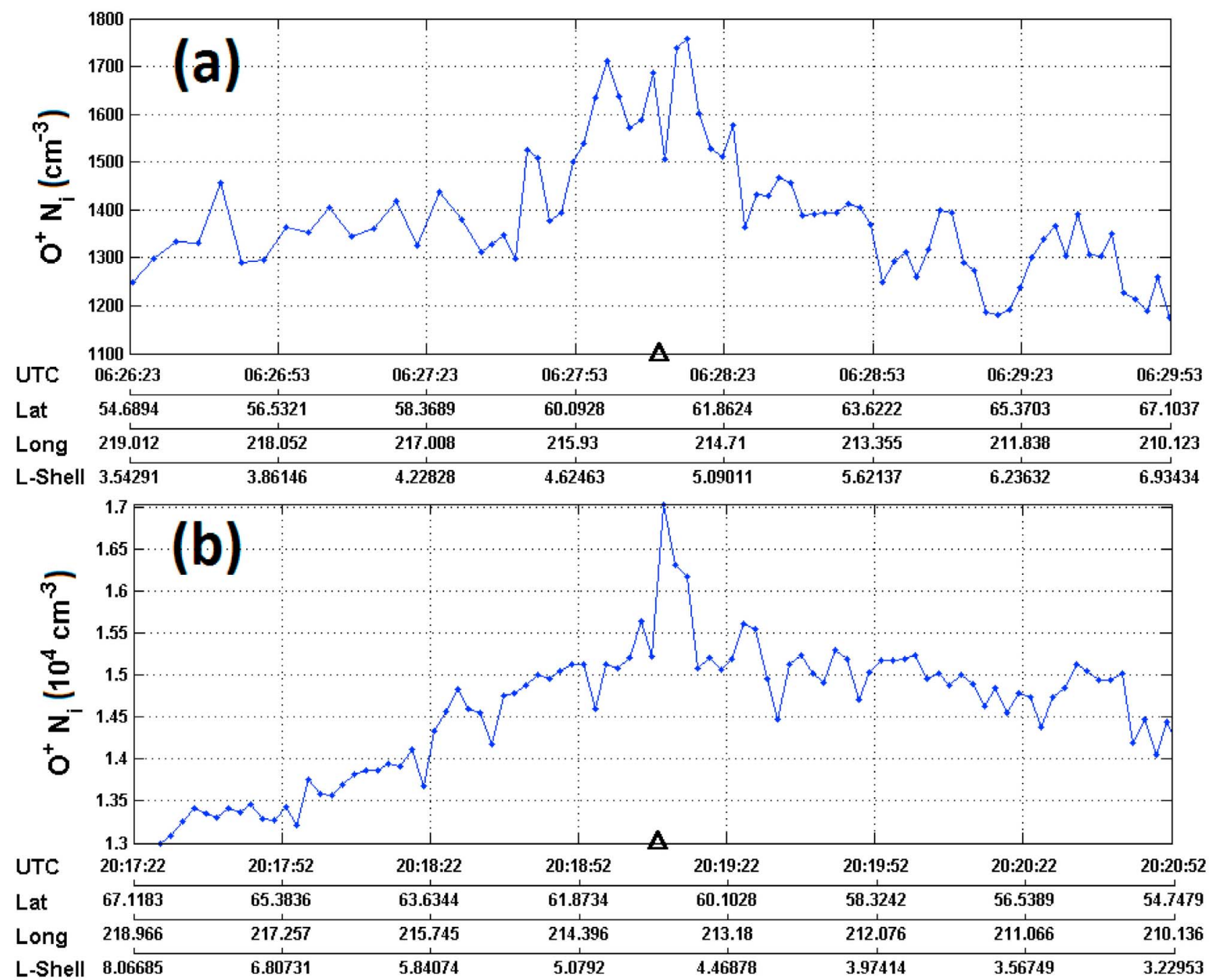

Figure 1. DEMETER observations of the $\mathrm{O}^{+}$ion density made on (a) 21 October 2009 and (b) 7 November 2010 along its orbit. The multiple scales on the $x$ axis show the time of observations in UT, satellite latitude, longitude, and L-shell.

shows a summary of relevant information for each heating experiment that detected artificial ionospheric ducts. Columns $1-7$ of Table 1 are: the date of the experiment and name of the satellite used; HF heating time; applied heating frequency $\left(\mathrm{f}_{\mathrm{H}}\right)$ and reflection height $\mathrm{h}$ (the absence of $\mathrm{h}$ in the table means that $\left.\mathrm{h}=\mathrm{h}_{\mathrm{m}} \mathrm{F}_{2}\right)$; ionospheric critical frequency $\left(\mathrm{f}_{\mathrm{o}} \mathrm{F}_{2}\right)$ and critical height $\left(\mathrm{h}_{\mathrm{m}} \mathrm{F}_{2}\right)$; the closest approach to the HAARP MZ $(\Delta \mathrm{R})$ and E-W half-power beam width at the heating altitude $\left(\mathrm{L}_{\mathrm{EW}}\right)$; the peak change in the fieldaligned ion velocity observed by the satellite $\left(\Delta \mathrm{V}_{\mathrm{i}}\right)$; and the relative deviation of the ion density in the duct observed by the satellite $\left(\Delta n_{i} / n_{i}^{0}\right)$. L $L_{E W}$ is assumed to be equal to the size of the heated region. Note that some experiments in column 3 marked with a "CW" indicate continuous wave heating, while in the rest of the experiments a square modulation of the HF wave was used (the modulation frequency ranged from $0.1-0.7 \mathrm{~Hz}$ ); the average power of the modulated wave is half that of the CW. In column 6 "N.A" indicates that the velocity measurement was either unavailable or inconclusive. Table 1 also lists the results of the ground based observations taken during satellite flyovers.
Namely, the eighth column reveals if reflections of the HF signals were detected by the Kodiak radar. Here the "strong" and "moderate" reflection indicate respectively 4-8 and 2-4 dB increase in the reflected signal intensity relative to that reflected from the ambient ionosphere. All the nighttime experiments in this column are marked by an "N.A.," which reflects the fact that the Kodiak radar cannot probe a weak nighttime ionosphere. Daytime experiments marked by an "N.A." indicate that the Kodiak radar was not available at that time. The ninth and final column shows the Geomagnetic Auroral Electrojet (AL index).

[10] Discussing the observational details of every experiment in Table 1 would be quite extensive, thus we will focus on only a few representative cases. Figure 1 shows observations made by DEMETER's IAP along its orbit during two different experiments. Namely, Figure 1a shows measurements of the $\mathrm{O}^{+}$ion density made during nighttime on 21 October, 2009. DEMETER's closest approach to the HAARP MZ occurred at 0628:08 UT/ 2228:08 LT (marked by the triangle) and was at a distance of about $27 \mathrm{~km}$. It should be noted that all latitudes and longitudes presented 


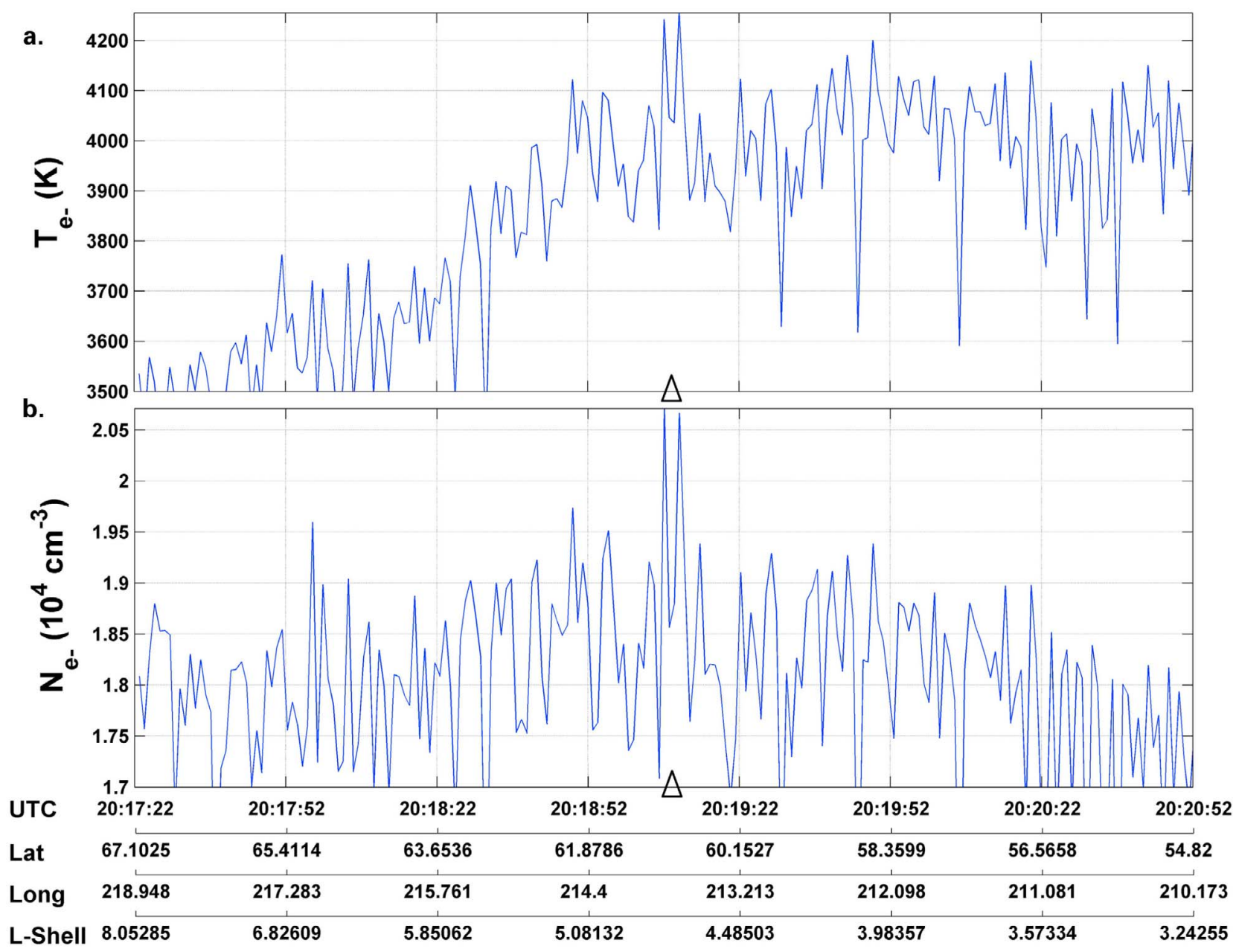

Figure 2. DEMETER observations made on 7 November 2010 showing the (a) electron temperature and (b) electron density.

in this paper are geographic. A distinct peak $\left(\Delta \mathrm{n}_{\mathrm{O}^{+}} / \mathrm{n}_{\mathrm{O}^{+}}^{0} \approx 21 \%\right)$ was detected when overflying the HAARP MZ, presumably caused by HF heating-induced plasma transport along the magnetic field. If we define the width of the $\mathrm{n}_{\mathrm{O}^{+}}$peak to be characterized by the full width at half maximum, we find that it is approximately $26 \mathrm{~s}$, which corresponds to about $190 \mathrm{~km}$ when DEMETER's orbital speed of $7.5 \mathrm{~km} / \mathrm{s}$ is considered. This is twice the size of the HF heated spot located near the $F_{2}$ peak at $230 \mathrm{~km}$, where the size of the HF-heated spot was estimated by taking into account that the half-power beam width at $\mathrm{f}_{\mathrm{H}}=2.8 \mathrm{MHz}$ is $20.2^{\circ}$ in the North-South plane (see the "IRI Performance Calculator" at www.haarp.alaska.edu). It should be noted that in the same experiment an intense stimulated electromagnetic emission was detected by DEMETER in the HF range [Milikh et al., 2011a]. This is an indication of strong ionospheric turbulence due to anomalous absorption near the $F_{2}$ peak.

[11] Figure 1b shows results of a daytime HAARP/ DEMETER experiment made on 7 November 2010. A distinct narrow peak of the $\mathrm{O}^{+}$ion density $\left(\Delta \mathrm{n}_{\mathrm{O}^{+}} / \mathrm{n}_{\mathrm{O}^{+}}^{0} \approx 13 \%\right)$ can be seen when overflying the HAARP MZ. Notice that the peak width is only about $10 \mathrm{~s}$, which corresponds to $75 \mathrm{~km}$, i.e., almost 3 times smaller than that during the nighttime. We will discuss this effect later on in the paper.
DEMETER's ISL instrument also detected ionospheric modification during this experiment; Figure 2 shows the electron temperature (Figure 2a) and total electron density (Figure 2b). Despite the Langmuir probe often being too noisy to be useful at HAARP's latitude, in this specific case a fairly distinct peak in electron temperature and density can be seen. As before, DEMETER's closest flyby to HAARP's $\mathrm{MZ}$ is marked by the triangle.

[12] We next discuss the HAARP/F16 DMSP experiments conducted on 9 February 2010 (Figures $3 \mathrm{a}$ and $3 \mathrm{~b}$ ) and 10 November 2010 (Figures 3c and 3d). Figure 3a shows the total ion density in $\mathrm{cm}^{-3}$ (solid line), and the $\mathrm{O}^{+}$ion density in $\mathrm{cm}^{-3}$ ( $\times$ markers), while Figure $3 \mathrm{~b}$ shows the upward field-aligned ion velocity, $V_{u p}(\mathrm{~m} / \mathrm{s}) ; V_{u p}=V_{v e r t} / \cos \left(\alpha_{0}\right)$, where $V_{\text {vert }}$ is the vertical ion velocity, and $\alpha_{0} \approx 14^{\circ}$ is the angle between the vertical and HAARP's MZ. Similarly, Figure $3 \mathrm{c}$ shows the total and $\mathrm{O}^{+}$ion densities, while Figure $3 \mathrm{~d}$ shows the upward field-aligned ion velocity. The $x$ axis gives the time (in seconds) measured relative to the time of the closest approach to the HAARP MZ, $T_{m z}$. One can clearly see distinct ion outflows of the width $\leq 160 \mathrm{~km}$ ( $\leq 20 \mathrm{~s}$ ) about $T_{m z}$, which is of the order of the HF-heated spot, has a change in field-aligned velocity of about $70 \mathrm{~m} / \mathrm{s}$ on 9 February 2010 and $250 \mathrm{~m} / \mathrm{s}$ on 10 November 2010; the 


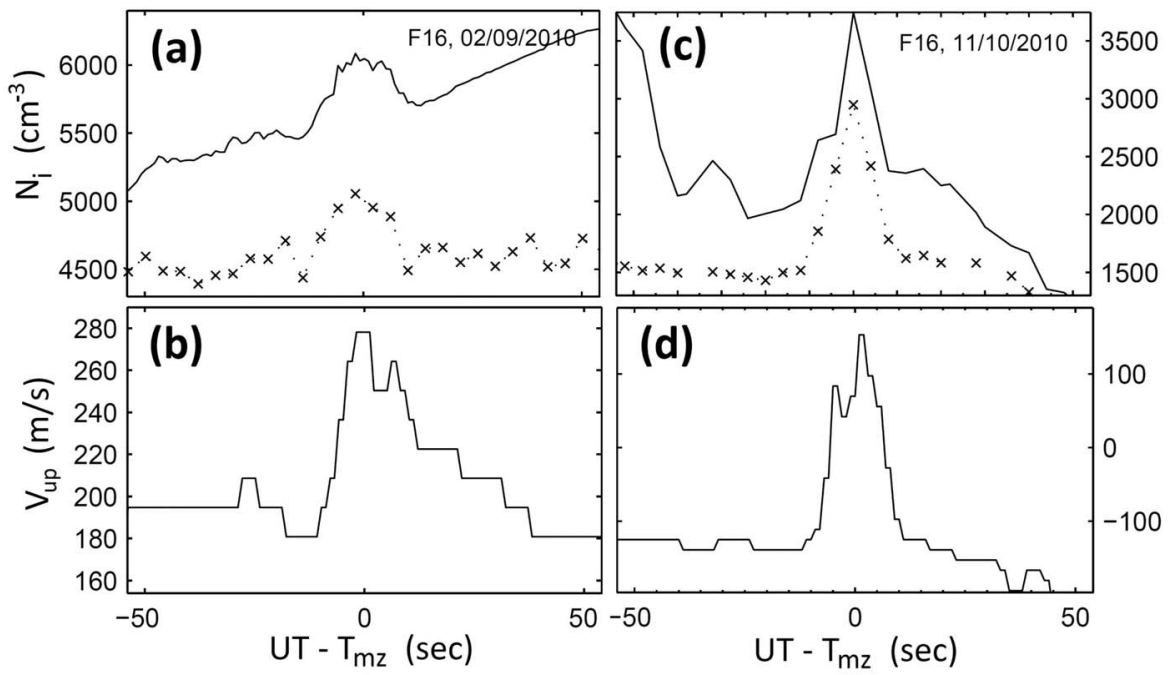

Figure 3. Observations made by the F16 DMSP satellite on 9 February 2010 (first column) and 10 November 2010 (second column). (a and c) The total ion density in $\mathrm{cm}^{-3}$ (solid trace), and the $\mathrm{O}^{+}$ion density in $\mathrm{cm}^{-3}$ ( $\times$ markers). ( $\mathrm{b}$ and $\mathrm{d}$ ) The upward field-aligned ion velocity in $\mathrm{m} / \mathrm{s}$. The time (in seconds) is given on the $x$ axis and is centered about $\mathrm{T}_{\mathrm{mz}}$ - the time of the closest approach to the HAARP MZ.

corresponding relative ion density perturbations are about $8 \%$ and $75 \%$, respectively. The large relative increase in density in the latter case can be attributed to the low ambient density of $2000 \mathrm{~cm}^{-3}$ and large change in ion outflow velocity of $250 \mathrm{~m} / \mathrm{s}$ compared to the $5500 \mathrm{~cm}^{-3}$ and $70 \mathrm{~m} / \mathrm{s}$ of the former case.

[13] It should be noted that the spatial profile of the ion outflow is similar to that of the local ion density, namely they both have a bell shape. This feature can be seen in the previously mentioned DMSP observations as well as in Figure 4a, which shows the ion density (top plot) and velocity (bottom plot) perturbations observed by DMSP F15 on 31 October 2010. Figure $4 \mathrm{~b}$ shows the corresponding Kodiak radar observations, which indicate strong reflection of the radar signals during the HF heating at around 0145 UT. This is indicative of the fact that turbulence was pumped into the $\mathrm{F}$ region plasma, leading to absorption of the HF wave power and creation of electron striations which reflect the radar signals.

[14] As we mentioned above, ground based diagnostics involve the HAARP Digisonde and the Kodiak radar. The Digisonde operates in a regular mode producing ionograms which help us choose a proper heating frequency, and in skymap mode for carrying out bottomside diagnostics of the heated region; the topside diagnostics are provided by the satellites. Figure 5 shows a Doppler skymap made during the HAARP/DEMETER experiment on 17 June 2010 at 2018:18 UT. The Digisonde uses its echo location capability to detect reflections of transmitted signals from irregular plasma structures in the ionosphere, marking the detected echoes on the skymap plane using their zenith and azimuth angles of arrival [Reinisch et al., 1998]. The color bar shows Doppler shift of each radio beam measured along the line of sight; negative Doppler shifts indicate upward motion.
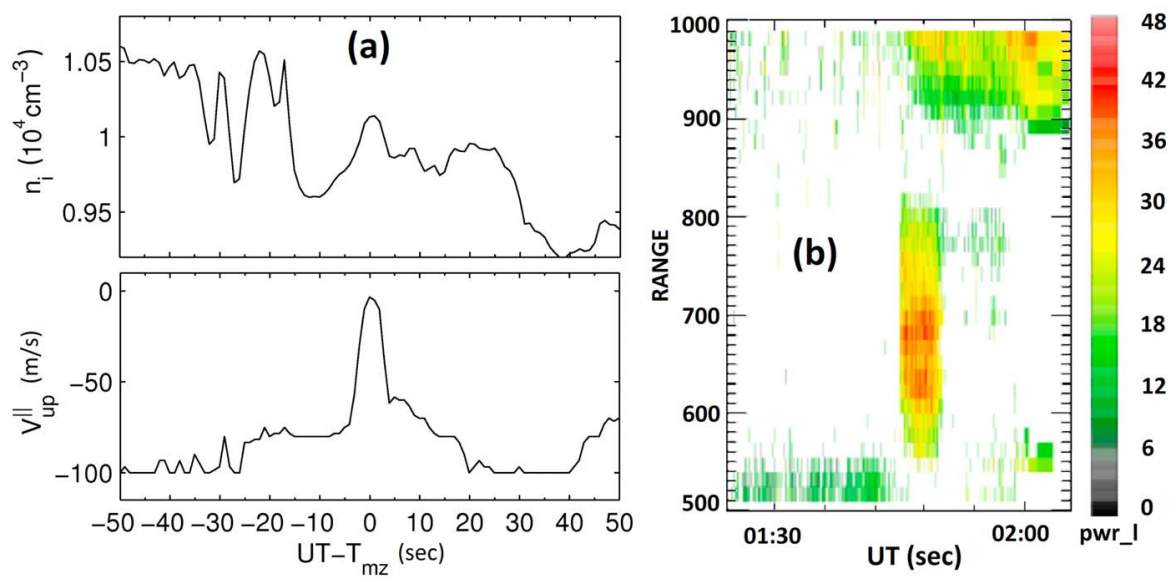

Figure 4. (a) Ion density/velocity (top and bottom, respectively) and the (b) corresponding Kodiak radar observations made on 31 October 2010 during the HAARP/F15 experiment. 


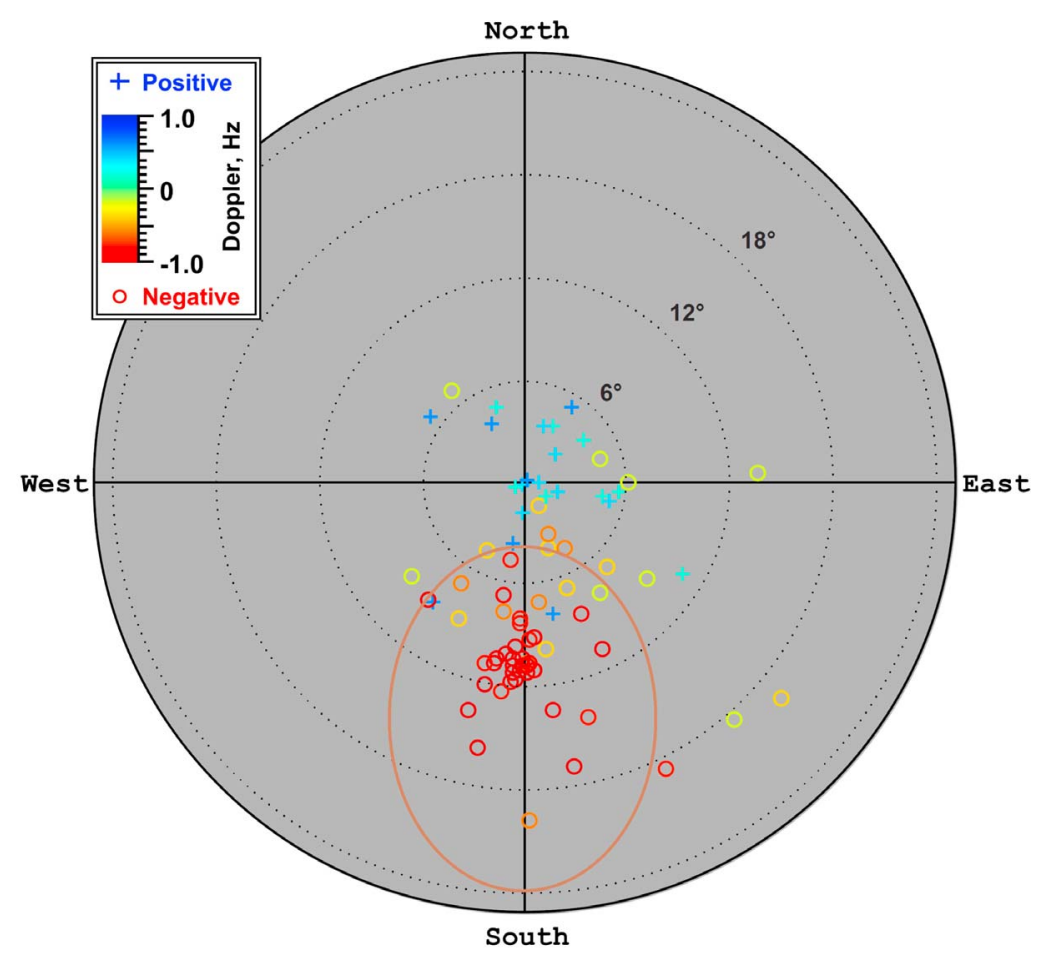

Figure 5. Doppler skymap made on 17 June 2010 during a HAARP/DEMETER experiment. The color bar shows Doppler shift of each radio beam measured along the line of sight with the negative Doppler shift indicating the upward motion. The ellipse represents HAARP's half-power angular beam size for the experiment.

The brown ellipse enclosing the cluster of echoes represents HAARP's half-power angular beam size for the experiment. The Digisonde probe frequency $\mathrm{f}_{\mathrm{p}}$ in Figure 5 is $3.91 \mathrm{MHz}$, well above the heater frequency of $\mathrm{f}_{\mathrm{H}}=2.85 \mathrm{MHz}$. This means that the probing frequency is reflected well above the height of maximum HF-wave/ionosphere interaction, thus reducing a possible source of error of the plasma drift calculations. Moreover as observed by Pedersen et al. [2009] and explained by Mishin and Pedersen [2011], significant production of ionization occurs due to accelerated suprathermal electrons below $180 \mathrm{~km}$, thus the probing wave in question would only be negligibly affected by ionization. Electron density time variations following HF heating are also a possible source of error since they can produce apparent Doppler shifts that are not attributed to bulk plasma motion alone. However, an estimate of the plasma loss rate at the relevant altitudes (see Appendix A) shows that electron density time variations can only create an apparent Doppler shift that would correspond to a drift speed of $\sim 7 \mathrm{~m} / \mathrm{s}$. This is not a negligible uncertainty; however it is much less than the plasma drift speed calculated below for this experiment, thus still showing that the plasma above the heated region is indeed moving upward.

[15] Figure 5 shows that during the HF heating a localized cluster of reflections appeared at $\pm 3^{\circ}$ centered around $12^{\circ}$, with their red color indicating a negative Doppler shift and thus an upwardly directed average ion speed. Soon after the heater was turned off the strong echoes from the MZ disappeared. Since the detected echoes come from the MZ, the measured line of sight velocity corresponds to the plasma motion along the magnetic field line. In earlier Digisonde studies, Scali et al. [1995] had validated the Digisonde line of site velocities by comparing collocated incoherent radar measurements with high altitude ionosonde measurements at Sondre Stromfjord, Greenland. It should be mentioned that Digisonde's skymap measurements cannot be made during heating due to strong small-scale turbulence. To get around this problem, during the heating schedule the heater is turned off for a few seconds, during which time the skymap data is acquired. This process is repeated several times throughout the heating schedule, and the final results are averaged to improve the accuracy of the results. It should also be noted that nighttime skymaps are not possible because there are too few of the necessary reflections that the Digisonde needs in order to produce them.

[16] Figure 6 shows Doppler shifts $\Delta f_{D}$ corresponding to the skymap data (Figure 5). Such plots are called "waterfalls"; here the x-axes give the Doppler shift in Hz, where the negative Doppler shifts correspond to upward motion. The echo locations shown in Figure 5 were measured at radar ranges of $250,255,260, \ldots, 285 \mathrm{~km}$. For each range the echo locations are calculated separately for each Doppler component using the phases at four spaced antennas. The negative Dopplers at the larger ranges are arriving from magnetic zenith. One would expect these oblique echoes to have a slightly larger radar range $(2-3 \%)$ than the vertical echoes. Note that because of the bulk motion of the ionospheric plasma different reflection points result in different Doppler shifts, thus explaining the Doppler spread. The Doppler shift for the magnetic zenith echoes is centered at 


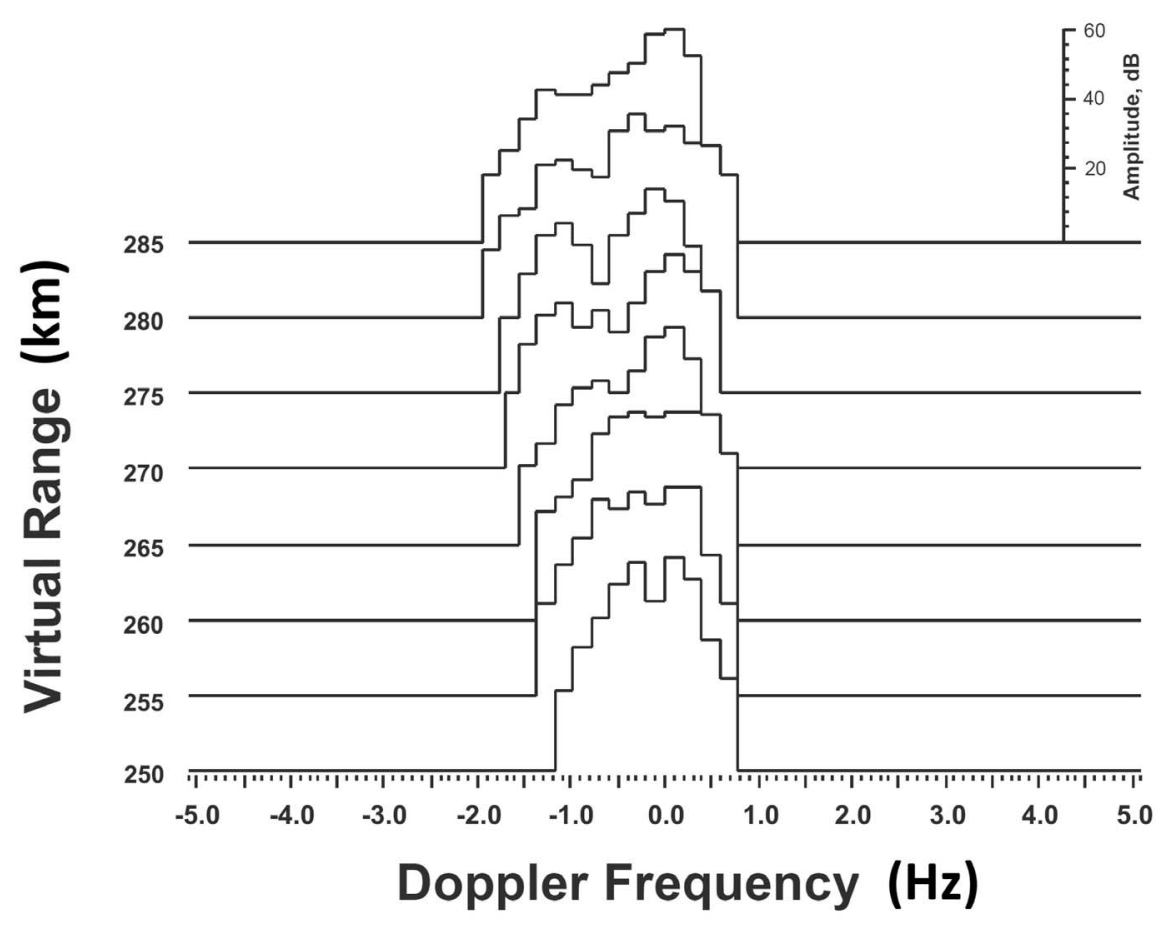

Figure 6. Doppler shift (horizontal axes) measured in $\mathrm{Hz}$ for a probing frequency of $3.91 \mathrm{MHz}$ at altitudes of $250,255,260, \ldots, 285 \mathrm{~km}$.

$-1.0 \mathrm{~Hz}$ corresponding to an upward flow velocity of $V_{u p}($ altitude $)=c\left(\Delta f_{D} / f_{p}\right) / 2$, which for the above experiment gives $V_{u p}(275 \mathrm{~km})=c\left(1 \mathrm{~Hz} / 3.91 \times 10^{6} \mathrm{~Hz}\right) / 2=38 \mathrm{~m} / \mathrm{s}$.

\section{Model Description}

[17] Here we present a computational model of the formation of artificial ducts due to HF heating of the ionosphere. The model is based on the SAMI2 code developed at the Naval Research Laboratory [Huba et al., 2000]. The SAMI2 model is inter-hemispheric and can simulate the plasma along the entire dipole magnetic field line (for the geometry of the model see Perrine et al. [2006]). We have modified SAMI2 by introducing in the model a flexible source of electron heating. This source of the electron heating was presented in the form of a localized heating rate per electron

$$
q(\mathrm{~K} / \mathrm{s})=q_{\text {peak }} e^{-\left(z-z_{0}\right)^{2} /(\Delta z)^{2}} e^{-\left(x-x_{0}\right)^{2} /(\Delta x)^{2}},
$$

where $q_{\text {peak }}$ is the peak electron heating rate and is typically given by $q_{\text {peak }}=\mu P /\left(k_{B} n_{e} V\right)$. Here $P$ is the total power of the transmitter, $n_{e}$ is the electron density, $k_{B}$ is Boltzmann's constant, $\mu$ is the absorption efficiency $(0<\mu<1), V$ is the volume of the heated region, and $\Delta \mathrm{z}$ and $\Delta \mathrm{x}$ are its vertical and North-South (N-S) horizontal half-sizes. The vertical offset, $z_{0}$, is set to the altitude of the $F_{2}$ peak provided by the HAARP Digisonde, while $\mathrm{x}_{0}$ represents N-S horizontal offset of the heated region.

[18] The HF-irradiated spot is an ellipse having a N-S angular half-widths $\Theta$ and $\mathrm{E}-\mathrm{W}$ angular half-widths $\Phi$, so that its semi-major axis $\Delta \mathrm{x}=z_{0} \tan \Theta$ and semi-minor axis
$\Delta y=z_{0} \tan \Phi ; \Theta$ and $\Phi$ depend on the irradiated frequency and are obtained from the HAARP website www.haarp. alaska.edu. Taking into account the vertical extent of the source gives us a volume for the HF-irradiated spot given approximately by $\mathrm{V}=(4 \pi / 3) \Delta x \Delta y \Delta z$. During critical heating it is assumed that electron heating occurs in an altitude range between the wave reflection point and the upper hybrid height, which is dominated by the anomalous absorption $(\Delta \mathrm{z} \approx 5 \mathrm{~km})$.

[19] The input parameters of the model are chosen to match the ionospheric conditions at HAARP during the specific time of the experiment. Namely, we use the proper $A_{p}$ and $F_{10.7}$ indexes in the SAMI2 model, and start/end the heating process at the times indicated in Table 1. Often the nominal settings of the model lead to a critical electron density significantly different than that observed by the HAARP Digisonde during the experiment. In such cases the neutral oxygen density of the model is properly adjusted to give an electron density profile that more closely matches the observations. In addition, its nominal settings can also lead to a significantly different topside electron density than that observed by the overflying satellite. Simultaneously matching both of the densities mentioned above to the corresponding observed values is not in general possible, making it difficult to get very close to the ionospheric conditions. Depending on the ionospheric conditions, one can take precedence over the other, and it is this that we end up matching in the model.

[20] The code starts up from empirically determined initial conditions $24 \mathrm{~h}$ before the specific heating time, and runs for $24 \mathrm{~h}$ of "world clock time." This practice allows the system to relax to ambient conditions, and reduces noise in the system due to the initialization. After the ambient ionosphere 

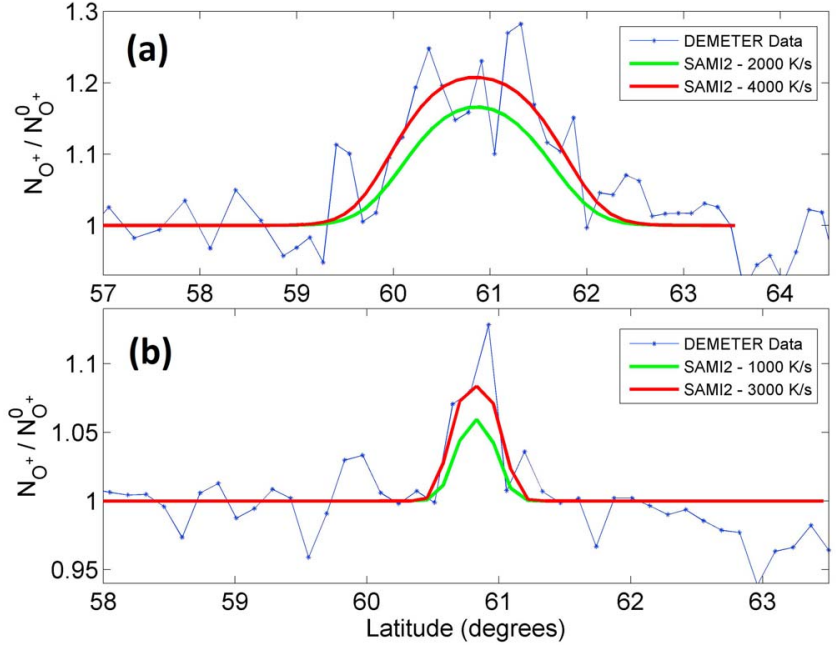

Figure 7. (a) DEMTER's measurements of the relative perturbations of $\mathrm{O}^{+}$density made on 21 October 2009 (connected points) along with SAMI2 model results (solid trace). (b) Observations and modeling for 7 November 2010.

is established, artificial heating is started and continuously pumps energy into the electrons at the specified altitude, and the perturbations in ion and electron properties are tracked as they travel along the field line. Then the heater switches off, allowing the ionosphere to relax back to ambient conditions.

[21] Earlier this model was validated by comparison with two well documented experiments. The first experiment was conducted at the EISCAT facility and diagnosed by the EISCAT Incoherent Scatter Radar, which measured the vertical profiles of the electron and ion temperature between 150 and $600 \mathrm{~km}$ [Rietveld, et al., 2003]. The second experiment was conducted at the SURA facility, and used the DEMETER satellite as a diagnostic tool to measure the ion density along the overflying satellite orbit close to the magnetic zenith of the HF heater [Frolov et al., 2008]. It was shown that the model reproduces observations with high accuracy, which establishes it as a key tool for the study of the artificial ionospheric modifications [Milikh et al., 2010a].

\section{Discussion}

[22] Now with the experimental results and model description presented, we move on to discussion and modeling results. Note that listed in Table 1 is the E-W width of the half power beam $\left(\mathrm{L}_{\mathrm{EW}}\right)$ along with the distance of the satellite's orbit from the center of the beam $(\Delta R)$. For close flyovers when $\Delta \mathrm{R} / \mathrm{L}_{\mathrm{EW}}<1$ the probability of duct detection strongly increases along with the duct amplitude measured $\Delta \mathrm{n}_{\mathrm{i}} / \mathrm{n}_{\mathrm{i}}$. During our HAARP experiments, essentially every time a satellite came close to the HAARP MZ while at the same time there being a perceptible ionospheric $F_{2}$ peak density, ionospheric ducts were detected. For more distant flyovers the current model should be modified, namely the angular distribution of the HAARP beam should be properly described outside of the half-power region as well.

[23] We now compare model results with the observations described in Section 2. Figure 7 shows comparison of the model results with the DEMETER nighttime and daytime observations of the relative $\mathrm{O}^{+}$density $\mathrm{n}_{\mathrm{i}} / \mathrm{n}_{\mathrm{i}}^{0}$ (from here on out we denote $n_{O^{+}}$by $n_{i}$ since $n_{O^{+}} \approx n_{i}$ at the relevant altitudes). The values of $n_{i} / n_{i}^{0}$ measured by DEMETER along its orbit during the nighttime on 21 October 2010 (Figure 7a) and during the daytime on 7 November 2010 (Figure 7b) are shown by the connected points; for both cases the "ambient" density corresponding to DEMETER's data was taken to be a constant along the orbit, and equal to the average of the density values to the left and right of the ducts. The curves show model results computed for different $T_{e}$ pumping rates. Since the HAARP beam width changes with the transmitted frequency, we adjusted the horizontal size of the heated region accordingly. Namely, at the $\mathrm{F}_{2}$ peak height (in this case $\sim 220 \mathrm{~km}$ ) the horizontal sizes for the above nighttime and daytime experiments were estimated to be about $80 \mathrm{~km}$ and $36 \mathrm{~km}$, respectively. The figure indicates fair agreement between the SAMI2 model predictions and the DEMETER observations. Note that the observed fine structure of the artificial ducts could be caused by large scale irregularities induced by the HF heating which in turn form irregularities inside the ducts when moving upward along the field line. Such process will be included in the duct model in the future.

[24] Figure 8 shows the DMSP measurements and results of the SAMI2 model for the HAARP/DMSP F16 experiments conducted on 9 February 2010. In Figure 8a, the modeled relative ion density is shown by the solid line, while the observations are marked by points having a relative density perturbation $\Delta n_{i} / n_{i}^{0}$ of about $8 \%$. Figure $8 b$ shows the SAMI2 computation of the upward ion outflow velocity, where the ambient velocity values have been subtracted away; the time between the chronologically numbered traces is about $2.5 \mathrm{~min}$, and trace 9 represents the first curve after heating has ended. The data point with the error bar toward the right shows the observation of the topside ion velocity (relative to its ambient value) made by the DMSP F16 satellite (column 6 of Table 1). It can be seen that the data point is quite close to the black solid trace, corresponding to the velocity profile during DMSP's closest overfly of the MZ at 1754:30 UT. The modeling for the conditions of this experiment was achieved with a heating rate of $700 \mathrm{~K} / \mathrm{s}$.

[25] We should mention that all SAMI2 comparisons were done assuming that the satellites' trajectories lie in HAARP's magnetic plane. In fact, the satellites' magnetic latitude varied by $3-5$ degrees during a given flyby near HAARP, while the magnetic longitude varied by $1.5-4.5$ degrees. Thus their deviations from the magnetic plane are relatively small. We expect the satellite observations made along their current orbits to be qualitatively similar to observations that would be made if their orbits were in the magnetic plane, especially for reasonably close flybys $(\Delta \mathrm{R}<60 \mathrm{~km})$.

[26] Properly describing the effects of the heated-region geometry and the satellite trajectory would require a 3D model. $\mathrm{E} \times \mathrm{B}$ drifts have also been neglected throughout our modeling. We are headed toward taking as much of the above into consideration as possible in our future work as we shift from using SAMI2 to using SAMI3.

\subsection{Calculation of Absorption Efficiencies}

[27] The results shown in Figure 8 allow us to estimate the HF wave's absorption efficiency $(\mu)$. For the 9 February 

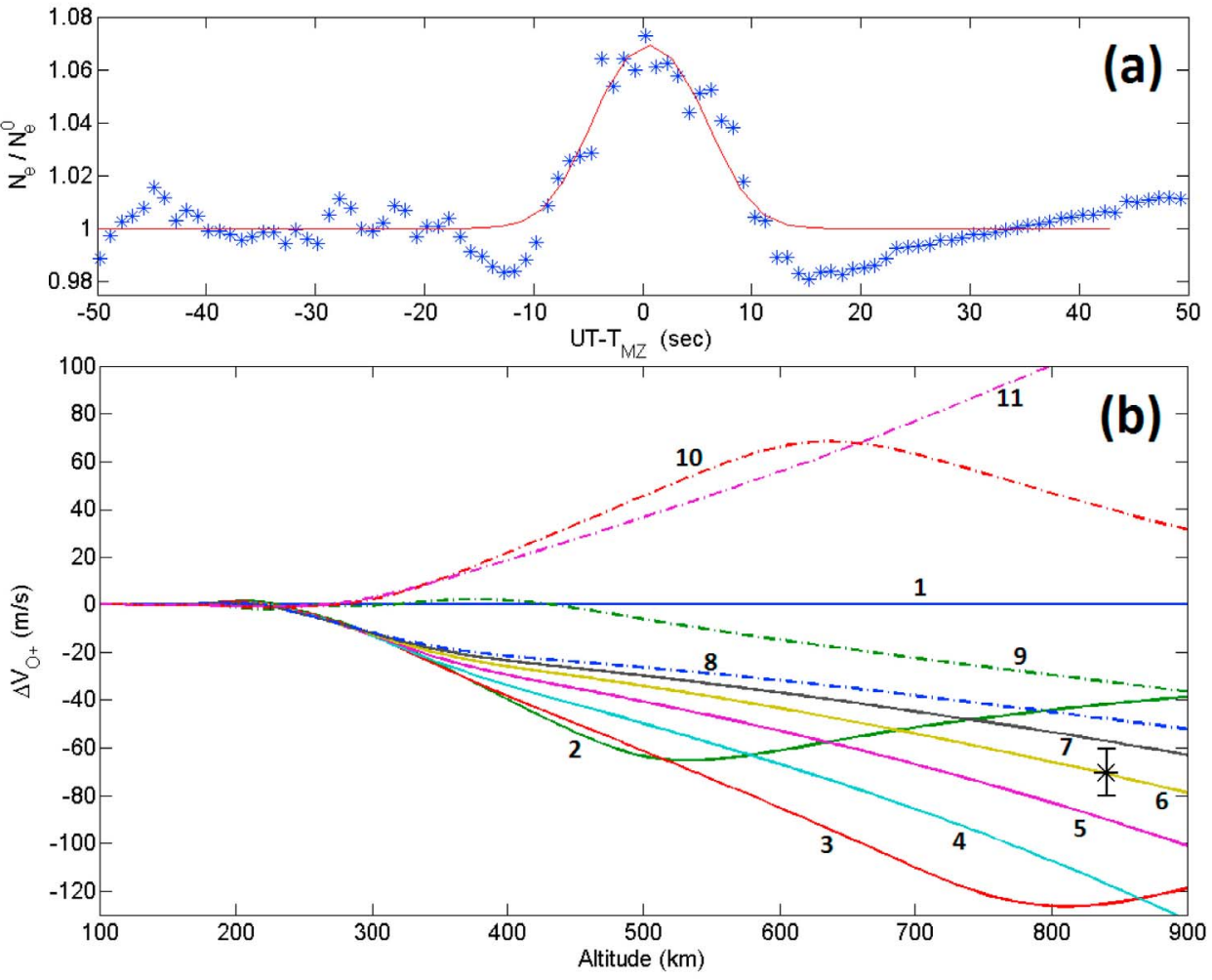

Figure 8. Results of the SAMI2 model for the HAARP/DMSP F16 experiments conducted on 9 February 2010. (a) The modeled relative perturbation of the electron density is shown by the solid line, while the observations are marked by points. (b) The SAMI2 computation of the upward ion outflow velocity, the time step between the chronologically numbered traces is about $2.5 \mathrm{~min}$. The data point with the error bar shows the observation made by F16. The modeling here was achieved with a heating rate of $700 \mathrm{~K} / \mathrm{s}$.

2010 daytime experiment the HAARP 2.8 MHz pump wave had a power density of $520 \mu \mathrm{W} / \mathrm{m}^{2}$ in the center of the heated region, at an altitude of $200 \mathrm{~km}$ near the wave reflection point, if wave absorption in the lower ionosphere is neglected. If we consider that the anomalous heating occurs in a $10 \mathrm{~km}$ thick layer near the reflection point, we obtain that the absorbed power density inside the layer is $52 \mathrm{nW} / \mathrm{m}^{3}$. Based on the ionogram during the experiment, the electron density near the reflection point was $9.7 \times$ $10^{10} \mathrm{~m}^{-3}$. If all of the above energy could be converted into electron heating, its heating rate could reach over $5 \times$ $10^{4} \mathrm{~K} / \mathrm{s}$ [cf. Gustavsson et al., 2001; Mishin et al., 2004]. However, according to the SAMI2 model the observed effect can be achieved with a heating rate of $700 \mathrm{~K} / \mathrm{s}$. Consider that the heating wave is significantly absorbed in the $\mathrm{D}$ and $\mathrm{E}$ regions during daytime experiments. We used an ionospheric HF heating code developed in the past [Papadopoulos et al., 2003] to estimate roughly how many $\mathrm{dB}$ of power is absorbed for our experiment. Running the code for the experimental conditions of 9 February 2010 (daytime, $\mathrm{f}_{\mathrm{H}}=2.8 \mathrm{MHz}, \mathrm{ERP}=84.1 \mathrm{dBW}$, O-mode) yields an absorbed power of about $5 \mathrm{~dB}$ for a quiet ionosphere and $10 \mathrm{~dB}$ for a normal ionosphere. Therefore the absorption efficiency can be estimated as $4-12.6 \%$. Note that Fallen et al. [2011] discussed a similar HAARP/DMSP F15 experiment by using their own 1D transport model. They found that a strong duct could be formed with only a $2.5 \%$ absorption efficiency. There exist many reasons that could account for the difference between this result and the results we obtained using SAMI2. For one thing, the experiment reported by Fallen et al. [2011] was performed during the nighttime, while our experiment was during the daytime. On the other hand, the SAMI2 model includes ion inertia, while the SCIM model used in Fallen et al. [2011] uses a hydrostatic approximation in its equation of motion and thus neglects the ion inertia. In any case, there are significant uncertainties associated with any heating rate estimates based on satellite measurements of topside density enhancements, and a close examination of the differences between heating rates of different experiments, especially ones modeled differently, is beyond the scope of this paper.

\subsection{Daytime Versus Nighttime Ducts}

[28] As is shown in Table 1, and discussed earlier in the paper, the daytime ducts are of smaller relative amplitude and narrower than the nighttime ducts as observed by DEMETER. In fact, the width of nighttime ducts reaches $200 \mathrm{~km}$ in the N-S direction versus $70-80 \mathrm{~km}$ of the daytime ducts. The density perturbation in the nighttime ducts reaches $20-40 \%$, while the daytime ducts are weaker than $15 \%$.

[29] Figure 9 shows the density distribution of artificial ducts at an altitude of $670 \mathrm{~km}$ computed by the SAMI2 model for the quiet ionospheric conditions of October 2009. 


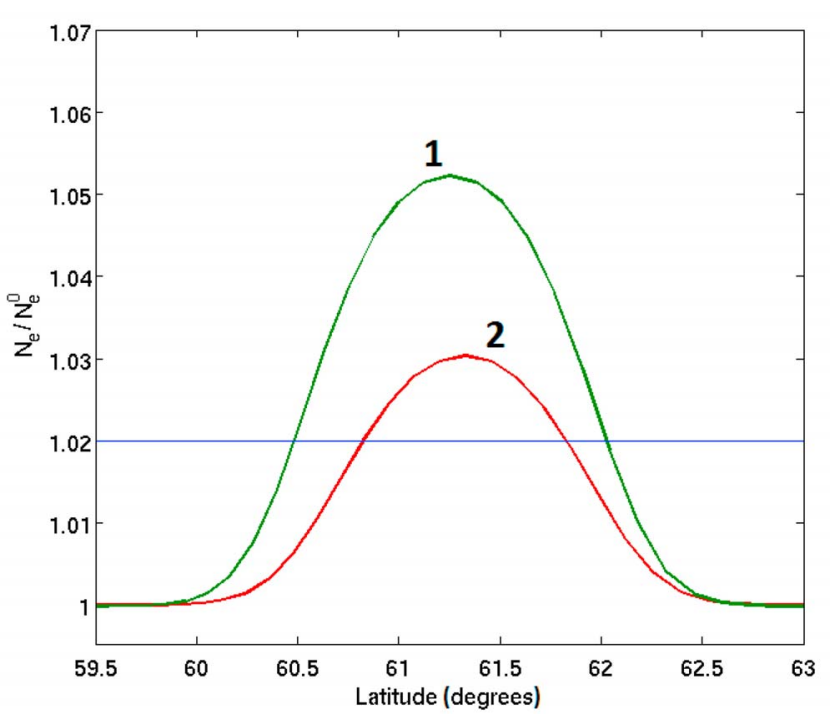

Figure 9. Electron density inside of a duct computed by the SAMI2 model for the quiet ionospheric conditions of October 2009. Trace 1 and trace 2 were computed for the nighttime and daytime condition, respectively, and show that an observational threshold (flat line) can give an appearance of significantly different widths.

The upper (trace 1) and bottom (trace 2) curves were computed for the nighttime and daytime condition, respectively. The absorption of the heating $\mathrm{HF}$ wave by the $\mathrm{D}$ region of the ionosphere was estimated as $3 \mathrm{~dB}$, thus the daytime pumping rate was reduced by $3 \mathrm{~dB}$ with respect to the nighttime conditions. This in turn produced a corresponding reduction of the duct amplitude. Moreover, the horizontal line in this figure represents an observational threshold of about $2 \%$, i.e., an assumption that artificial density perturbations of $\Delta \mathrm{n}_{\mathrm{i}} / \mathrm{n}_{\mathrm{i}}<2 \%$ cannot be distinguished from the ionospheric noise. Note that the observational threshold depends upon the ionospheric conditions, and the specific value of $2 \%$ is used only for illustration purpose. The observational threshold cuts off the undetectable part of the duct, and thus defines the duct's width; in fact the nighttime duct in Figure 8 is 1.5 times broader than the daytime duct.

[30] As was noted in the introduction of this section, a higher frequency pump wave is required during daytime conditions than during nighttime, sometimes by as much as a factor of 2, thus reducing the size of the daytime heated region. This, in addition to the threshold of detection mentioned above, gives a satisfactory explanation of why daytime ionospheric ducts are observed to be narrower than that of nighttime.

\section{Conclusions}

[31] Artificial ducts in the topside ionosphere over HAARP have been detected on a regular basis by the DEMETER and DMSP satellites during four HAARP/BRIOCHE campaigns in 2009 and 2010. Overall, the plasma density enhancements detected between 0930 and 1230 LT varied from $3 \%-13 \%$, while those during $\sim 1730-2215$ LT were typically $15-40 \%$. The duct magnitudes and widths provided by the modified SAMI 2 model agree fairly well with the satellite observations. The ducts seem to be produced most efficiently for heating frequencies quite close to the critical frequency $\mathrm{f}_{\mathrm{o}} \mathrm{F}_{2}$.

\section{Appendix A: Plasma Loss Rate Estimate}

[32] The measurement of bulk plasma drifts using a Digisonde relies on the Doppler shifts of probing waves reflecting off of small scale irregularities in the bulk plasma. However, Doppler shifts of a probing wave can in addition be attributed to plasma loss rates; here we estimate the role played by the time variation of the electron density following HF heating. HF heating produces strong Langmuir type plasma turbulence near the HF reflection point. The vertical extent of the perturbed layer, $\Delta \mathrm{z}$ (not to be confused with the vertical extent of anomalous heating in Section 3), is approximately $1 \mathrm{~km}$ for the HAARP conditions [Milikh et al., 2011b]. The perturbed layer will decay due to electron-ion recombination, thus producing a Doppler shift of the original probing wave. This Doppler shift will manifest itself as a plasma drift with velocity $V_{d}$.

[33] If we take the perturbed density in the perturbed layer to be $\delta n_{e}$ and take the recombination time to be $\tau_{r e c}$, then the drift velocity can be estimated as follows:

$$
\begin{gathered}
\frac{d\left(\delta n_{e}\right)}{d t}=\frac{d\left(\delta n_{e}\right)}{d z} \frac{d z}{d t}=\frac{d\left(\delta n_{e}\right)}{d z} V_{d} \\
\frac{d\left(\delta n_{e}\right)}{d t} \sim-\frac{\delta n_{e}}{\tau_{r e c}} \Rightarrow V_{d} \sim-\left(\delta n_{e} \frac{d z}{d\left(\delta n_{e}\right)}\right) \frac{1}{\tau_{r e c}}=-\frac{\Delta z}{\tau_{r e c}}
\end{gathered}
$$

where the quantity $\delta n_{e} \frac{d z}{d\left(\delta n_{e}\right)}$ is recognized as being the vertical extent of the perturbed layer, $\Delta z$. The negative sign in the expression for the drift velocity indicates that the drift is upward. The recombination time [Schunk and Nagy, 2000] is given by

$$
\tau_{r e c}=\frac{1}{2 \alpha_{e i}^{e f f} n_{e}}
$$

where $\alpha_{e i}^{e f f}$ is the effective recombination rate, which is dominated by dissociative recombination of $\mathrm{NO}^{+}$and $\mathrm{O}_{2}^{+}$ ions. Thus, we can express the effective recombination rate as

$$
\alpha_{e i}^{e f f}=\alpha_{e i}^{N O^{+}} \frac{n_{N O^{+}}}{n_{e}}+\alpha_{e i}^{O_{2}^{+}} \frac{n_{O_{2}^{+}}}{n_{e}}
$$

where $n_{\mathrm{NO}^{+}} / n_{e}$ and $n_{\mathrm{O}_{2}^{+}} / n_{e}$ are the fractions of the respective ions. The expression for the drift speed can now be written as

$$
V_{d} \approx-2 \Delta z\left(\alpha_{e i}^{N O^{+}} n_{N O^{+}}+\alpha_{e i}^{O_{2}^{+}} n_{O_{2}^{+}}\right)
$$

The dissociative recombination rates (as a function of electron Temperature) of the individual ions $\left(\alpha_{e i}^{\mathrm{NO}^{+}}, \alpha_{e i}^{\mathrm{O}^{+}}\right)$ are taken from [Schunk and Nagy, 2000, Table 8.5].

[34] What remains is to input the relevant ionospheric profiles in order to calculate the upward ion drift. This is achieved by inputting the date of the experiment into 


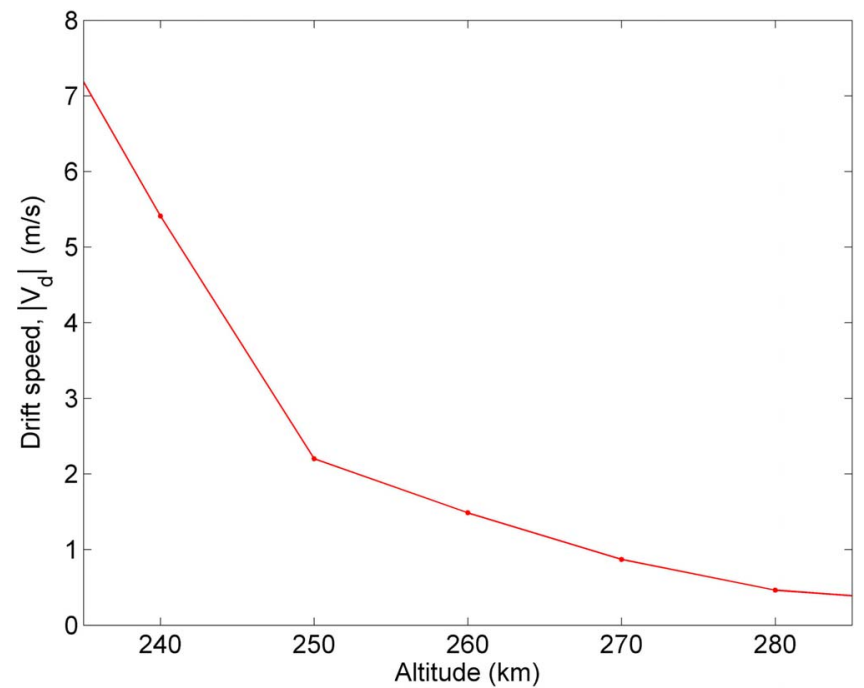

Figure A1. Estimate of drift speed that would be observed due to an apparent Doppler shift of a probing wave caused by time variations of electron density following HF heating.

NASA's IRI model and insisting that the $\mathrm{f}_{\mathrm{o}} \mathrm{F}_{2}$ matches the Digisonde observations during the experiment $(\sim 4 \mathrm{MHz})$. Note that the irregularities that reflected the probing radio waves were between $250 \mathrm{~km}$ and $285 \mathrm{~km}$ (see Figure 6), while the azimuthal angle of the reflected probing waves was between 0 and 20 degrees. Therefore the reflection height of the probing radio wave ranges between 235 and $285 \mathrm{~km}$. The computed drift speed profile for the above range is shown in Figure A1. It can be seen that for the experiment under interest the drift velocity due to the decay of plasma turbulence is under $\sim 7 \mathrm{~m} / \mathrm{s}$, and could be considered as an inaccuracy when compared to the observed drift speed of $38 \mathrm{~m} / \mathrm{s}$.

[35] Acknowledgments. A.V. and G.M. were supported by DARPA via a subcontract N684228 with BAE Systems and also by the MURI grant N000140710789. E.M. was supported by the Air Force Office of Scientific Research. The authors thank J.J. Berthelier for the use of the data from the IAP instrument onboard DEMETER. We are also very thankful for Lee Snyder's help with the Digisonde measurements and for the Kodiak radar measurements made by Bill Bristow.

[36] Robert Lysak thanks the reviewers for their assistance in evaluating this paper.

\section{References}

Carpenter, D., et al. (2002), Small-scale field-aligned plasmaspheric density structures inferred from the Radio Plasma Imager on IMAGE, J. Geophys. Res., 107(A9), 1258, doi:10.1029/2001JA009199.

Fallen, C. T., J. A. Secan, and B. J. Watkins (2011), In-situ measurements of topside ionosphere electron density enhancement during an HF-modification experiment, Geophys. Res. Lett., 38, L08101, doi:10.1029/ 2011GL046887.

Frolov, V., V. Rapoport, G. Komrakov, A. Belov, G. Markov, M. Parrot, J. Rauch, and E. Mishin (2008), Density ducts formed by heating the
Earth's ionosphere with high-power HF radio waves, JETP Lett., 88 , 790, doi:10.1134/S002136400824003X

Gustavsson, B., et al. (2001), First tomographic estimate of volume distribution of HF-pump enhanced airglow emission, J. Geophys. Res., 106 , 29,105-29,123, doi:10.1029/2000JA900167.

Huba, J., G. Joyce, and J. Fedder (2000), Sami2 is another model of the ionosphere (SAMI2), A new low-latitude ionosphere model, J. Geophys. Res., 105, 23,035-23,053, doi:10.1029/2000JA000035.

Koons, H. (1989), Observations of large-amplitude, whistler-mode wave ducts in the outer plasmasphere, J. Geophys. Res., 94, 15,393-15,397, doi:10.1029/JA094iA11p15393.

Milikh, G. M., and A. Vartanyan (2010), HAARP-induced ionospheric ducts, in Modern Challenges in Nonlinear Plasma Physics, edited by D. Vassiliadis et al., pp. 185-191, Am. Inst. of Phys., Melville, N. Y.

Milikh, G. M., K. Papadopoulos, H. Shroff, C. Chang, T. Wallace, E. Mishin, M. Parrot, and J. Berthelier (2008), Formation of artificial ionospheric ducts, Geophys. Res. Lett., 35, L17104, doi:10.1029/ 2008GL034630.

Milikh, G. M., A. Demekhov, K. Papadopoulos, A. Vartanyan, J. Huba, and G. Joyce (2010a), Model for artificial ionospheric duct formation due to HF heating, Geophys. Res. Lett., 37, L07803, doi:10.1029/ 2010GL042684

Milikh, G. M., et al. (2010b), Ion outflows and artificial ducts in the topside ionosphere at HAARP, Geophys. Res. Lett., 37, L18102, doi:10.1029/ 2010GL044636.

Milikh, G. M., A. Vartanyan, K. Papadopoulos, and M. Parrot (2011a), Focusing of HF radio-waves by ionospheric ducts, J. Atmos. Solar Terr. Phys., 73, 1674-1680, doi:10.1016/j.jastp.2011.02.022.

Milikh, G. M., K. Papadopoulos, B. Eliasson, and X. Shao, and E. Mishin (2011b), Artificial emissions and formation of ionized layers in the ionosphere due to HF-heating, Abstract SA42A-07 presented at 2011 Fall Meeting, AGU, San Francisco, Calif., 5-9 Dec.

Mishin, E., and T. Pedersen (2011), Ionizing wave via high-power HF acceleration, Geophys. Res. Lett., 38, L01105, doi:10.1029 2010GL046045.

Mishin, E. V., W. J. Burke, and T. Pedersen (2004), On the onset of HF-induced airglow at magnetic zenith, J. Geophys. Res., 109, A02305, doi:10.1029/2003JA010205.

Papadopoulos, K., T. Wallace, M. McCarrick, G. Milikh, and X. Yang (2003), On the efficiency of ELF/VLF generation using HF heating of the auroral electrojet, Plasma Phys. Rep., 29, 561-565, doi:10.1134 1.1592554 .

Pedersen, T., et al. (2009), Optical ring formation and ionization production in high-power HF heating at HARP, Geophys. Res. Lett., 36, L18107, doi:10.1029/2009GL040047.

Perrine, R., G. Milikh, K. Papadopoulos, J. Huba, G. Joyce, N. Swisdak, and Y. Dimant (2006), An interhemispheric model of artificial ionospheric ducts, Radio Sci., 41, RS4002, doi:10.1029/2005RS003371.

Reinisch, B., J. Scali, and D. Haines (1998), Ionospheric drift measurements with ionosondes, Ann. Geofis., 41, 695.

Rich, F., and M. Hairston (1994), Large-scale convection patterns observed by DMSP, J. Geophys. Res., 99, 3827-3844, doi:10.1029/93JA03296.

Rietveld, M., M. Kosch, N. Blagoveshchenskaya, V. Kornienko, T. Leyser, and T. Yeoman (2003), Ionospheric electron heating, optical emissions, and striations induced by powerful HF radio waves at high latitudes: Aspect angle dependence, J. Geophys. Res., 108(A4), 1141, doi:10.1029/2002JA009543.

Scali, J. L., B. W. Reinisch, C. J. Heinselman, and T. W. Bullett (1995), Coordinated digisonde and incoherent scatter radar $F$ region drift measurements at Sondre Stromfjord, Radio Sci., 30(5), 1481-1498, doi: $10.1029 / 95 R S 01730$.

Schunk, R. W., and A. Nagy (2000), Ionospheres: Physics, Plasma Physics, and Chemistry, 2nd ed., Cambridge Univ. Press, New York.

Streltsov, A. V., M. Lampe, and G. Ganguli (2007), Whistler propagation in nonsymmetrical density channels, J. Geophys. Res., 112, A06226, doi:10.1029/2006JA012093. 